
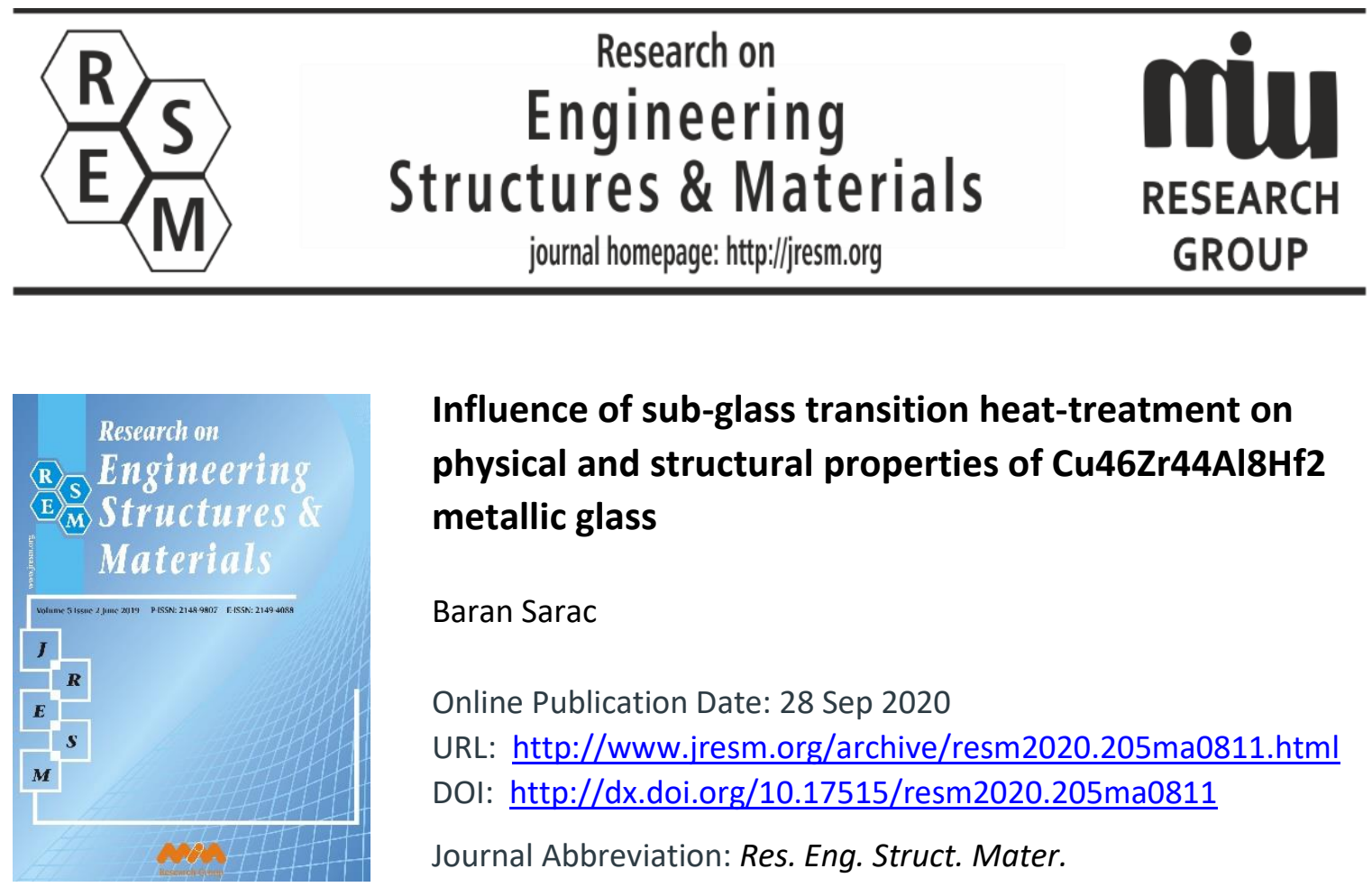

\title{
Influence of sub-glass transition heat-treatment on physical and structural properties of Cu46Zr44Al8Hf2 metallic glass
}

\section{Baran Sarac}

Online Publication Date: 28 Sep 2020

URL: http://www.jresm.org/archive/resm2020.205ma0811.html DOI: http://dx.doi.org/10.17515/resm2020.205ma0811

Journal Abbreviation: Res. Eng. Struct. Mater.

\section{To cite this article}

Sarac B. Influence of sub-glass transition heat-treatment on physical and structural properties of Cu46Zr44AI8Hf2 metallic glass. Res. Eng. Struct. Mater., 2021; 7(1): 121-134.

\section{Disclaimer}

All the opinions and statements expressed in the papers are on the responsibility of author(s) and are not to be regarded as those of the journal of Research on Engineering Structures and Materials (RESM) organization or related parties. The publishers make no warranty, explicit or implied, or make any representation with respect to the contents of any article will be complete or accurate or up to date. The accuracy of any instructions, equations, or other information should be independently verified. The publisher and related parties shall not be liable for any loss, actions, claims, proceedings, demand or costs or damages whatsoever or howsoever caused arising directly or indirectly in connection with use of the information given in the journal or related means.

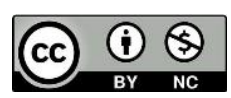

Published articles are freely available to users under the terms of Creative Commons Attribution - NonCommercial 4.0 International Public License, as currently displayed at here (the "CC BY - NC"). 


\section{Research on Engineering Structures \& Materials}

journal homepage: http://jresm.org

\section{Influence of sub-glass transition heat-treatment on physical and structural properties of $\mathrm{Cu}_{46} \mathrm{Zr}_{44} \mathrm{Al}_{8} \mathrm{Hf}_{2}$ metallic glass}

\section{Baran Sarac}

Erich Schmid Institute of Materials Science, Austrian Academy of Sciences, 8700 Leoben, Austria

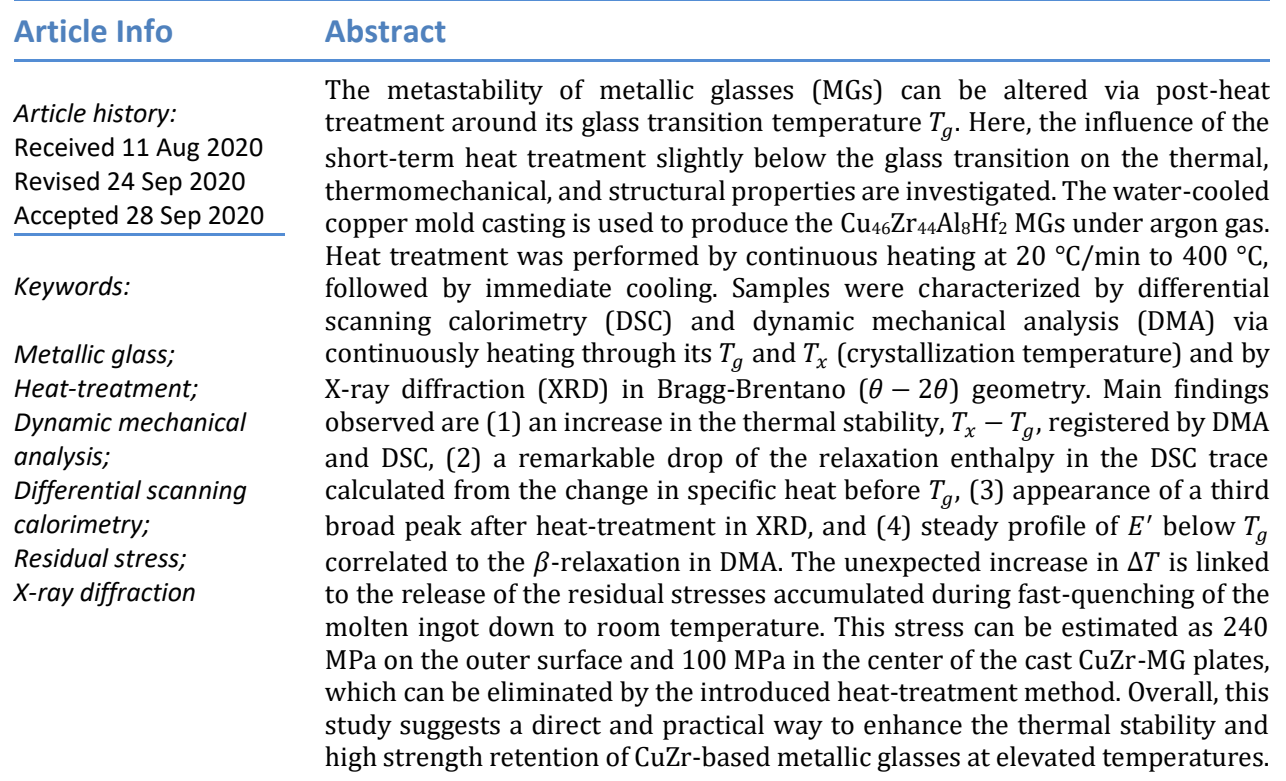

\section{Introduction}

The thermodynamic behavior of complex alloy systems can reveal additional information such as mechanical damping, vibration-induced phase transformations and sensitive defect investigation compared to the conventional static-type characterization [1-7]. The instantaneously reversible elasticity, time-delayed viscoelasticity and time-dependent irreversible viscoplasticity are investigated experimentally and theoretically by applying a small vibrational load, which can be done at constant frequency or a range of frequencies during continuous heating or isothermal treatment [8-13]. Dynamic mechanical analysis (DMA) is nowadays used to identify the changes in the storage $E^{\prime}$ and loss $E^{\prime \prime}$ moduli as a function of the glass transition and crystallization events of amorphous metallic alloys socalled (bulk) metallic glasses (B)MGs [14-24].

The transition of the metastable glasses to a stable configuration is called physical aging or structural relaxation by the annihilation of excess free volume [25], while isoconfigurational glassy state dynamics obey the Arrhenius behavior [26, 27]. The relaxation phenomenon has two major components: main $(\alpha)$ and secondary ( $\beta$ or excess wing) $[28,29]$. The $\alpha$ relaxation is mainly linked to the cooperative motion of atoms or 
molecules in the liquid, whereas the secondary relaxation can be described as the local noncooperative motion of molecules or atoms [30,31]. Some metallic glass classes show a prominent $\beta$-relaxation peak $[32,33]$, whereas others do not show a pronounced secondary peak but an excess wing of the $\alpha$ relaxation peak $[29,34,35]$.

In the class of metallic glass, CuZr-MGs exhibit appealing glass-forming ability with cooling rates down to $10 \mathrm{~K} / \mathrm{s}$, allowing them to be cast into mm-thick samples [36]. They possess higher yield strength (up to $2.5 \mathrm{GPa}[37,38]$ ) close to the theoretical limit, up to $2.6 \%$ elastic strain at room temperature $[39,40]$, and acceptable fracture toughness of up to 100 $\mathrm{MPa} \mathrm{m}^{-1 / 2}$ [41]. Recent investigations on the isothermal annealing of BMGs below the glasstransition temperature $T_{\mathrm{g}}$ revealed the pronounced changes in terms of mechanical and thermal properties due to the structural relaxation, and in turn, the annihilation of free volume stored in MGs upon casting [42-55]. Among them, Li et al. has shown that although no pronounced changes are observed for the DSC trace, annealing close to sub- $T_{\mathrm{g}}$ for a long duration can lead to brittle behaviour with nearly-zero fracture energy [43]. The long-term thermal annealing at temperatures below $T_{\mathrm{g}}$ for Zr-containing metallic glasses was proven to originate from the temporary structural relaxation with an additional endotherm in the glass transition region, which can be fully reversed by the subsequent heat treatment for a short term above $T_{\mathrm{g}}$ [42]. Thus, the endotherm observed in differential scanning calorimetry (DSC) right after $T_{\mathrm{g}}$ is accounted for by the time-dependent relaxation process during sub- $T_{\mathrm{g}}$ annealing. Another study from the same group has shown that the difference between the fictive (determined from calorimetry) and critical fictive (determined from annealing and 3-point bend test) temperatures defines their mechanical behaviour and its sensitivity to rate of cooling and annealing conditions [56]. In addition to the annihilation of free volume, phase devitrification can be also observed for the $\mathrm{Zr}_{57} \mathrm{Ti}_{8} \mathrm{Nb}_{2.5} \mathrm{Cu}_{13.9} \mathrm{Ni}_{11.1} \mathrm{Al}_{7.5}$ [57] and $\mathrm{Zr}_{55} \mathrm{Cu}_{30} \mathrm{Al}_{10} \mathrm{Ni}_{5}$ [58] alloys depending on the isothermal treatment temperature and time.

It has been confirmed in the literature that the sub- $T_{\mathrm{g}}$ annealing induced structural reordering of $\mathrm{Cu}$ and $\mathrm{Zr}$ atoms leads to limited diffusion on the nanometer-scale registered by the synchrotron X-ray diffraction (XRD), which eventually results in considerable compressive plasticity [58-60]. This improvement was linked to the chosen heat treatment path: continuous heating to the desired sub- $T_{\mathrm{g}}$, wait for several minutes until the temperature is stabilized, followed by rapid cooling to the desired temperature. For the $\mathrm{Zr}_{35} \mathrm{Ti}_{30} \mathrm{Cu}_{7.5} \mathrm{Be}_{27.5}$ with larger glass forming ability, our group has proven that the mechanical properties of the 2D honeycombs [46] and periodic heterostructures [45] do not alter for long-term isothermal heat treatment (18 $\mathrm{h}$ and below) even if the sub- $T_{\mathrm{g}}$ annealing is performed only $25^{\circ} \mathrm{C}$ below its glass transition.

The influence of sub- $T_{\mathrm{g}}$ annealing on CuZr-based metallic glasses was also studied in detail by our group. In the first study, $\mathrm{Cu}_{46} \mathrm{Zr}_{44} \mathrm{Al}_{8} \mathrm{Hf}_{2}$ composition was used, and various characterizations including DSC, dilatometry, 3-point bend-test, parallel-plate rheometry, XRD and transmission electron microscopy was conducted on a range of heat-treated samples below and above its $T_{\mathrm{g}}$ [49]. In the second article, by using the same material, we have analysed the differences in the atomic configuration on the optimized sample (heattreated at $400{ }^{\circ} \mathrm{C}$ ) and the as-cast state using reciprocal and real space analysis with the data acquired from the synchrotron XRD measurements [61].

Here, we present that the thermomechanical, thermophysical and structural properties of $\mathrm{Cu}_{46} \mathrm{Zr}_{44} \mathrm{Al}_{8} \mathrm{Hf}_{2}$ metallic glasses are altered by continuous heating and subsequent cooling treatment. Thin sheets prepared from the mm-sized cast plate were subjected to $\mu \mathrm{m}$-scale oscillating displacements in a 3-point bending mode. $E^{\prime}, E^{\prime \prime}$ and $\tan \delta$ values, particularly 
around the supercooled liquid region and sub-glass transition were compared to the ascast state sample. The structural properties of each sample were characterized by XRD, whereas the continuous heating traces of the standard DSC were comparatively evaluated. The modifications are linked to the residual stresses imposed during casting and their release via the post-heat treatment process.

\section{Material and Method}

The master alloy of $\mathrm{Cu}_{46} \mathrm{Zr}_{44} \mathrm{Al}_{8} \mathrm{Hf}_{2}$ was prepared from elements with purity higher than 99.99\% by arc-melting (Edmund Bühler $\mathrm{GmbH}$ ) in an argon atmosphere purified by Ti getter. The master alloys were heated above the liquidus temperature three times to homogenize the ingot. The water-cooled copper mold casting into plate shape with $75 * 10$ * $1 \mathrm{~mm}^{3}$ was conducted under the Ar atmosphere using an in-situ suction casting device attached to Edmund Bühler Arc Melter. Part of the rods was inserted in the TA Discovery Hybrid Rheometer DHR-3 and brought to $400{ }^{\circ} \mathrm{C}$ at a heating rate of $20^{\circ} \mathrm{C} / \mathrm{min}$ under $\mathrm{N}_{2}$ atmosphere. After a lag time of 5 seconds, samples were immediately cooled to $150{ }^{\circ} \mathrm{C}$ at a cooling rate of $50{ }^{\circ} \mathrm{C} / \mathrm{min}$ and subsequently water-quenched to room temperature. All the samples were ground and polished, where the final samples were $8.0 \pm 1.0 \mathrm{~mm}$ in length and $4.5 \pm 0.3 \mathrm{~mm}$ in width with a thickness of $0.50 \pm 0.05 \mathrm{~mm}$. Differential scanning calorimetry (DSC) measurements were performed with a Mettler Toledo DSC 3+ under Ar atmosphere at a constant heating rate of $20^{\circ} \mathrm{C} / \mathrm{min}$ with $20.0 \pm 0.5 \mathrm{~g}$ polished samples. Dynamic mechanical analysis (DMA) was performed in three-point bending mode using a TA Discovery Hybrid Rheometer DHR-3 in the temperature range $50{ }^{\circ} \mathrm{C}-600{ }^{\circ} \mathrm{C}$ with a heating and cooling rate of $10{ }^{\circ} \mathrm{C} / \mathrm{min}$ and a frequency of $1 \mathrm{~Hz}$ for a $20 \mu \mathrm{m}$ oscillation displacement which generates the oscillation stress. A constant preload of $25 \mathrm{~N}$ was applied. Nitrogen was used as purging gas during the experiments. The samples were examined by X-ray diffraction (XRD) in Bragg-Brentano $(\theta-2 \theta)$ geometry using a Bruker D2Phaser diffractometer with Co K $\alpha$ radiation $(\lambda=1.7089 \AA)$ using a step size of 0.02 .

\section{Results}

Since the temperature stabilization can be precisely controlled and rapidly satisfied in the DMA furnace, the samples were cooled immediately after heating (with a lag time of 5 seconds). This procedure is different from the previous heat treatment studies performed in a standard calibrated furnace, where 5 minutes of isothermal heat treatment was applied both for temperature stabilization and atomic reconfiguration [49]. Figure 1 compares the as-cast sample with the heat-treated sample at $400^{\circ} \mathrm{C}$ for 5 minutes. The first broad amorphous X-ray diffraction maximum does not visibly change upon heat treatment, whereas the second broad maximum shifts slightly towards a larger $2 \theta$ (Table 1). In amorphous structures, X-rays are scattered in many directions yielding a broad diffraction peak distributed in a wide range of $2 \theta$ instead of high intensity narrower peaks [62]. The first and second broad amorphous X-ray diffraction maximum, $\mathrm{Q}_{1}=1.36 \AA^{-1}$ and $\mathrm{Q}_{2}=2.35$ $\AA^{-1}$, respectively, is defined by the configuration of the nearest neighbor shell atoms. A detailed synchrotron XRD analysis using the same composition was performed by our group, which indicates the probabilities of the most abundant atomic pairs, $\mathrm{Zr}-\mathrm{Cu}$, followed by $\mathrm{Cu}-\mathrm{Cu}$ and $\mathrm{Zr}-\mathrm{Zr}$, respectively [61]. A third peak for the heat-treated sample at $101^{\circ}$ with $Q_{3}=5.42 \AA^{-1}$ emerges due to the reconfiguration of these atomic pairs within the amorphous clusters. Thus, compared to our previous XRD findings [49, 61], the heat treatment environment and time for heat treatment seems to influence the type of medium-to-long-range order changes. 


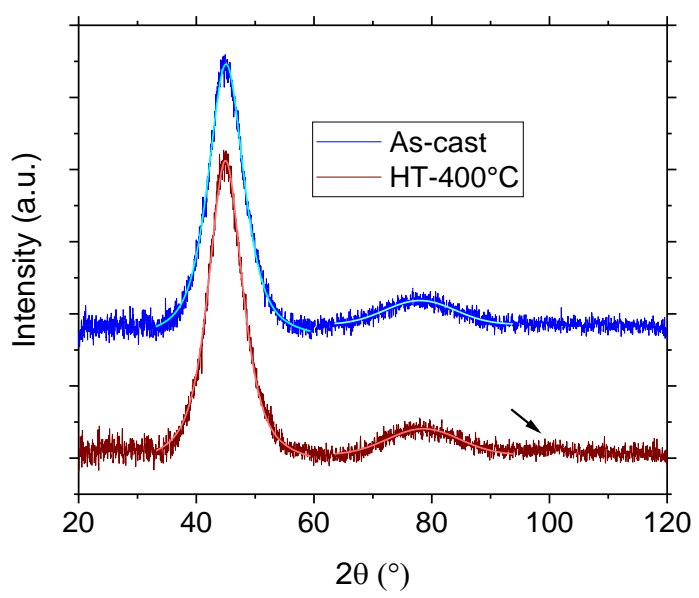

Fig. 1 X-ray diffraction patterns of the as-cast (blue) and heat-treated at $400{ }^{\circ} \mathrm{C}$ (wine). The black arrow indicates the small hump observed for the HT $-400^{\circ} \mathrm{C}$ sample. Pseudo-

Voigt fitting (Cyan and light red colors) was applied to find the peak positions.

The DSC traces of the as-cast and $\mathrm{HT}-400^{\circ} \mathrm{C}$ samples in Figure 2 registered the slight shift in $T_{\mathrm{g}}$ towards smaller temperatures (by $5^{\circ} \mathrm{C}$ ). On the other hand, no change is observed for the crystallization temperature $\left(T_{\mathrm{x}}=510^{\circ} \mathrm{C}\right)$. Thus, the supercooled liquid region (SCLR), $\Delta T=T_{\mathrm{x}}-T_{\mathrm{g}}$, becomes larger with the short-term sub- $T_{\mathrm{g}}$ heat treatment, confirming the existence of structural modifications observed in the XRD diffractogram. The relaxation enthalpy before the relaxation endotherm, $\Delta H_{\text {relax, }}$ shows a pronounced decrease as well as the change in the shape of the area, i.e. for the HT $-400^{\circ} \mathrm{C}$ sample, specific heat $\left(c_{\mathrm{p}}\right)$ does not drop during relaxation as in the case for the as-cast samples. Thus, similar to our previous study, the stored free-volume in the metallic glass during casting is partially consumed by this heat treatment process without a significant degree of change in $T_{g}$ and $T_{\mathrm{x}}$ [60].

Since the temperature stabilization can be precisely controlled and rapidly satisfied in the DMA furnace, the samples were cooled immediately after heating (with a lag time of 5 seconds). Figure 3 shows the before and after DMA measurement image of the representative as-cast sample. The metallic shiny and flat samples deform in the SCLR due to the dramatic drop in viscosity by roughly an order of magnitude per every $20^{\circ} \mathrm{C}$ increase [63-65]. As a result, the samples were bent $\sim 90^{\circ}$ under small amounts of applied loads $(25$ $\mathrm{N}$ ), while the surface was oxidized and became black. 


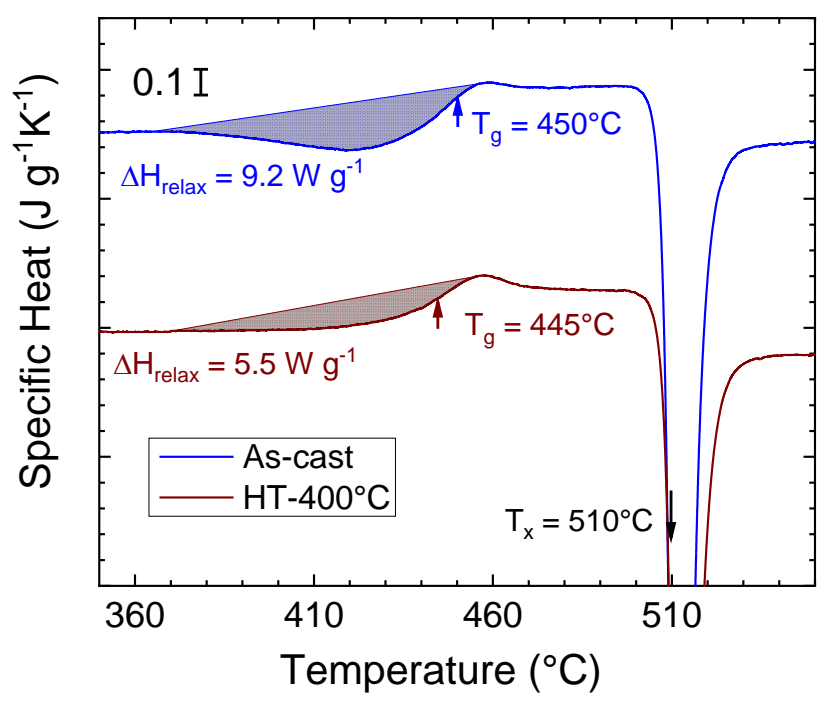

Fig. 2 Specific heat calculated from the DSC traces as a function of temperature for the as-cast (blue) and $\mathrm{HT}-400^{\circ} \mathrm{C}$ (wine) samples. $T_{\text {gas-cast }}=450 \pm 2{ }^{\circ} \mathrm{C}, T_{\mathrm{g}_{\mathrm{HT}-400^{\circ} \mathrm{C}}}=445 \pm 2$ ${ }^{\circ} \mathrm{C}, T_{\mathrm{x}}=510 \pm 2{ }^{\circ} \mathrm{C}, \Delta H_{\text {relax as-cast }}=9.2 \pm 0.5 \mathrm{~W} \mathrm{~g}^{-1}$, and $\Delta H_{\text {relax }_{\mathrm{HT}-400^{\circ} \mathrm{C}}}=5.5 \pm 0.5 \mathrm{~W} \mathrm{~g}^{-1}$.

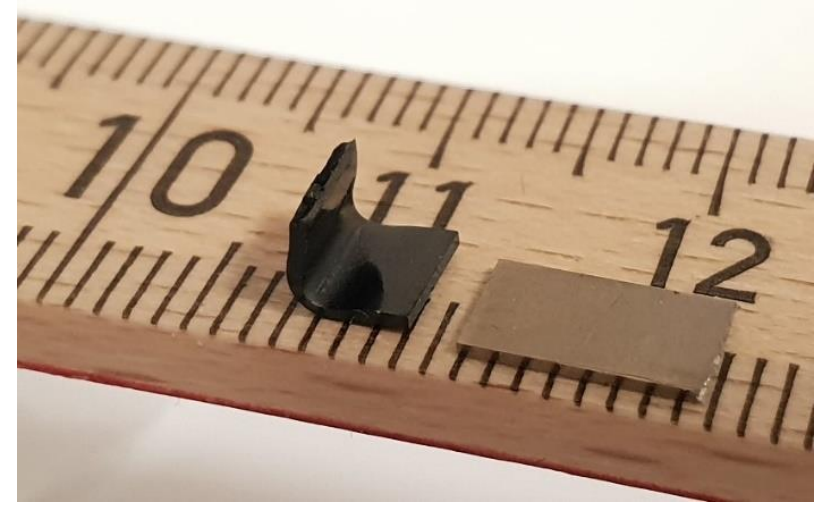

Fig. 3 CuZr-based MG samples prepared for the three-point bending test. The flat, metallic gray sample (right) is the representative as-cast state sample-the sample bents during continuous heating in its SCLR under a small static load (left).

The deformation profiles of the as-cast and $\mathrm{HT}-400^{\circ} \mathrm{C}$ samples are displayed in Figure $4 \mathrm{a}$. A relatively constant storage modulus is observed for both samples until $275^{\circ} \mathrm{C}$. After this temperature, the as-cast state sample stiffens by the rise of the storage modulus $E^{\prime}$ from $99 \mathrm{GPa}$ to $110 \mathrm{GPa}$. On the other hand, no remarkable change of the $E^{\prime}=105 \mathrm{GPa}$ for the $\mathrm{HT}-400^{\circ} \mathrm{C}$ is observed. This is because of the increase in $E^{\prime}$ below $T_{\mathrm{g}}$ related to $\beta$-transition disappears after the sub- $T_{\mathrm{g}}$ heat treatment. The $T_{\mathrm{g}}$ determined from the $E^{\prime}$ onset (intersection of the dashed lines in Figure $4 \mathrm{~b}$ ) yields the values of 427 and $415^{\circ} \mathrm{C}$ for the 
as-cast and $\mathrm{HT}-400^{\circ} \mathrm{C}$, respectively. Since the $T_{\mathrm{g}}$ determined from the $E^{\prime}$ onset being related to mechanical failure, it can be concluded that the sub- $T_{\mathrm{g}}$ annealing causes embrittlement, which can lead to early catastrophic failure, as reported in $[42,45,46,56]$. After full crystallization, the storage modulus immediately exceeds the storage modulus of the initial states.

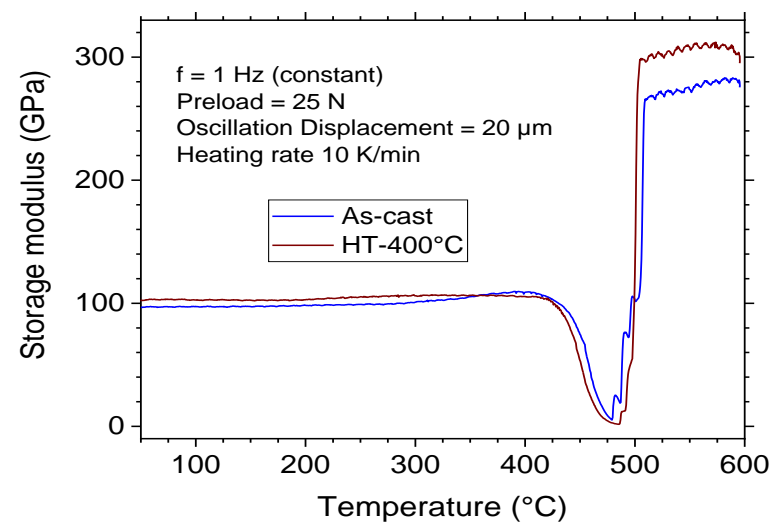

(a)

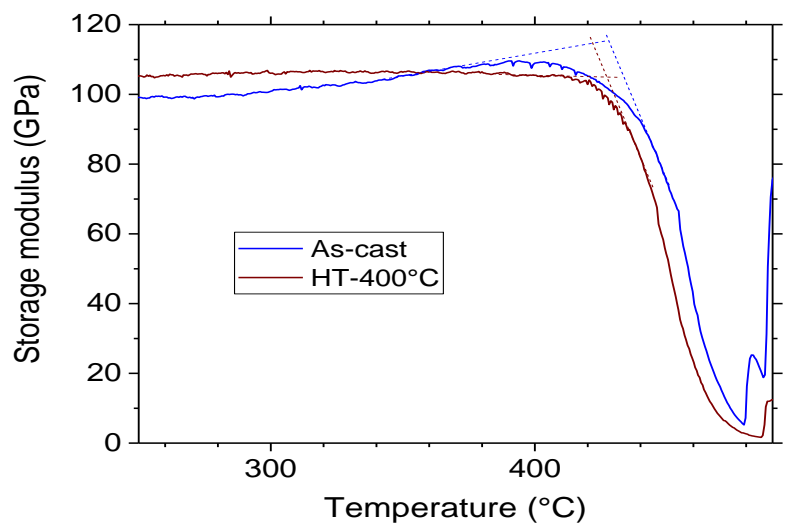

(b)

Fig. 4 (a) Overview and (b) magnified traces of the storage modulus ( $\left.E^{\prime}\right)$ vs. temperature $(T)$ of the MG determined from three-point bending, under continuous heating at a heating rate of $10^{\circ} \mathrm{C} / \mathrm{min}$ and a frequency of $1 \mathrm{~Hz}$ between $50^{\circ} \mathrm{C}$ and 600 ${ }^{\circ} \mathrm{C}$. The temperature accuracy is within $\pm 2{ }^{\circ} \mathrm{C}$.

Figure 5 a depicts the loss modulus, $E^{\prime \prime}$, as a function of temperature. $T_{\mathrm{g}}$ values determined from the $E^{\prime \prime}$ peaks are $455{ }^{\circ} \mathrm{C}$ and $447{ }^{\circ} \mathrm{C}$ for the as-cast and $\mathrm{HT}-400^{\circ} \mathrm{C}$ samples, respectively. This peak corresponds to the temperatures where the viscous drop already begins, and thus, is more closely related to the physical property changes obtained from the differential scanning calorimetry (c.f. Figure 2). Compared to $E^{\prime}$ and $E^{\prime \prime}$, $\tan \delta=E^{\prime \prime} / E^{\prime}$ shows the peak at the highest temperature; for the as-cast and $\mathrm{HT}-400^{\circ} \mathrm{C}$ samples, these values are $479^{\circ} \mathrm{C}$ and $485^{\circ} \mathrm{C}$, respectively. This point corresponds to the bottom points at the $E^{\prime}$ vs. $T$ graph in Figure $4 \mathrm{~b}$, indicating the full crystallization, $T_{\mathrm{x}}$. The extent of the SCLR 
is larger for the heat-treated sample, corroborating our DSC results. It is known that the height and shape of the $\tan \delta$ peak change systematically with amorphous content. $\tan \delta_{\max }$ for the $\mathrm{HT}-400^{\circ} \mathrm{C}$ is 1.14 , much higher than the 0.68 ; moreover, it is slightly broader than the as-cast state sample. The summary of the findings of the DSC, DMA and XRD studies are given in Table 1.

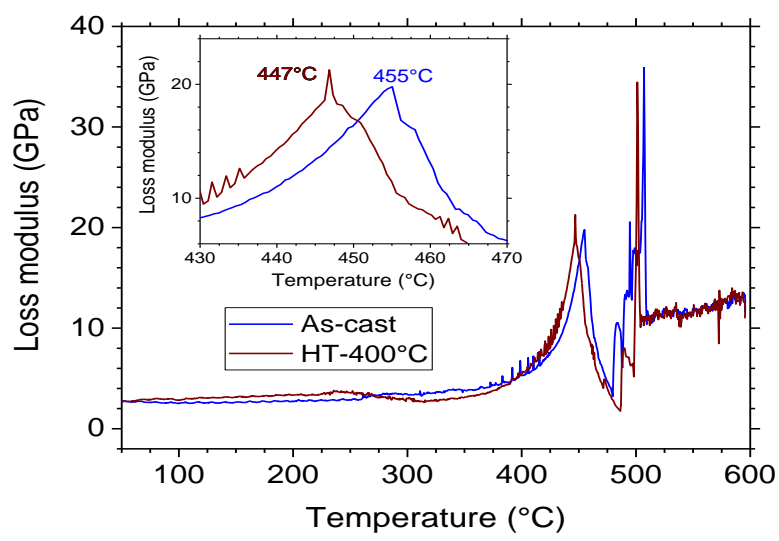

(a)

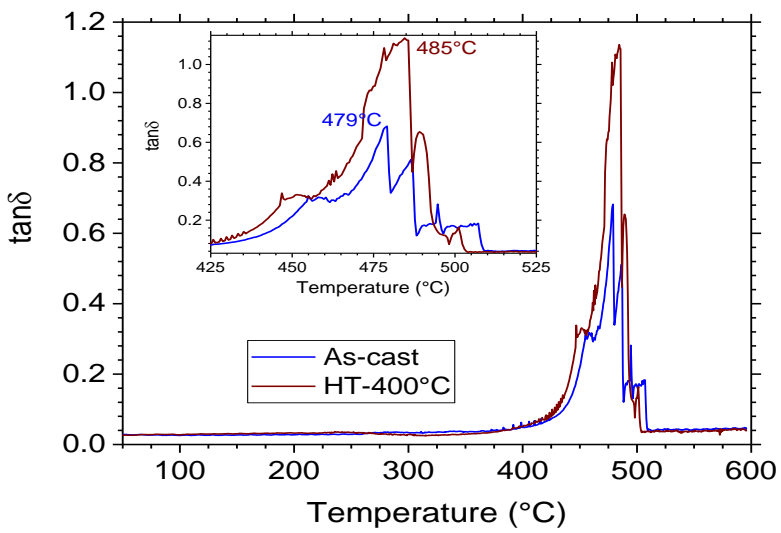

(b)

Fig. 5 (a) The loss modulus ( $\left.E^{\prime \prime}\right)$ and (b) $\tan \delta$ vs. temperature $(T)$ of the MG determined from three-point bending, under continuous heating at a heating rate of 10 ${ }^{\circ} \mathrm{C} / \mathrm{min}$ and a frequency of $1 \mathrm{~Hz}$ between $50^{\circ} \mathrm{C}$ and $600{ }^{\circ} \mathrm{C}$. The temperature accuracy is within $\pm 2{ }^{\circ} \mathrm{C}$.

Our findings hint that the as-cast state sample might have residual stresses imposed upon casting, which can arrest the free volume in MGs. On the other hand, the post-heat treatment releases these stresses and contributes to the free volume. The residual stresses imposed on the sample upon quenching and the influence of post-heat treatment on the stress release are shown in the discussion part. 
Table 1. Comparison of DSC, DMA and XRD data of the as-cast and heat-treated samples. Note that the temperature accuracy for the DSC and DMA measurements is within $\pm 2{ }^{\circ} \mathrm{C}$, and the enthalpy of relaxation is within $\pm 0.5 \mathrm{~W} \mathrm{~g} \mathrm{~g}^{-1}$; the storage and loss modulus is within $\pm 3 \mathrm{GPa}$, and XRD accuracy is within $\pm 0.02^{\circ}$.

\begin{tabular}{ccccc}
\hline DSC & $T_{\mathrm{g}}\left({ }^{\circ} \mathrm{C}\right)$ & $T_{\mathrm{x}}\left({ }^{\circ} \mathrm{C}\right)$ & $\Delta T\left({ }^{\circ} \mathrm{C}\right)$ & $\begin{array}{c}\Delta H_{\text {relax }} \\
\left(\mathrm{W} \mathrm{g}^{-1}\right)\end{array}$ \\
\hline As-cast & 450 & 510 & 60 & 9.2 \\
$\mathrm{HT}-400^{\circ} \mathrm{C}$ & 445 & 510 & 65 & 5.5 \\
\hline DMA & $T_{\mathrm{g}}\left({E^{\prime}}^{\prime}\right.$ nse $\left.^{-}{ }^{\circ} \mathrm{C}\right)$ & $T_{\mathrm{g}}\left({E^{\prime \prime}}_{\text {peak }}{ }^{\circ} \mathrm{C}\right)$ & $T_{\mathrm{x}}\left(\tan \delta_{\text {peak }}{ }^{\circ} \mathrm{C}\right)$ & $\Delta T^{\prime}\left({ }^{\circ} \mathrm{C}\right)$ \\
\hline As-cast & 427 & 455 & 479 & 52 \\
$\mathrm{HT}-400^{\circ} \mathrm{C}$ & 415 & 447 & 485 & 70 \\
\hline DMA & $\Delta T^{\prime \prime}\left({ }^{\circ} \mathrm{C}\right)$ & $\mathrm{E}^{\prime} @ 275^{\circ} \mathrm{C}$ & $\mathrm{E}_{\text {onset }}^{\prime}$ & $\tan \delta$ \\
\hline As-cast & 24 & 99 & 110 & 0.68 \\
HT- $400^{\circ} \mathrm{C}$ & 38 & 105 & 105 & 1.14 \\
\hline XRD & $1^{\text {st }}$ peak $\left({ }^{\circ}\right)$ & $2^{\text {nd }}$ peak $\left({ }^{\circ}\right)$ & $3^{\text {rd }}$ peak $\left({ }^{\circ}\right)$ & \\
\hline As-cast & 45.06 & 78.02 & N $/ \mathrm{A}$ & \\
HT- $400^{\circ} \mathrm{C}$ & 44.96 & 78.60 & 101.02 & \\
\hline
\end{tabular}

\section{Discussion}

The cooling rate of a plate can be estimated from the finite element modeling of the BMG ingots fabricated by the copper mold casting, where the obtained cooling rates of samples were in a linear agreement with the variation of sample diameter [66]. For the plate geometry, the equation to obtain the cooling rate $R$ was slightly modified as:

$$
R=15800 /(\sqrt{4 *(w * t) / \pi})^{1.92}
$$

where $w$ and $t$ are the width and thickness of the cast plate, respectively. For $t=1 \mathrm{~mm}$ and $w=10 \mathrm{~mm}$, the cooling rate can be estimated as $R \sim 1375^{\circ} \mathrm{C} / \mathrm{s}$. For metallic glasses, a remarkable slow-down is viscosity, and in turn, the atomic mobility is observed due to the decrease in the number of metastable configurations that glass can be present [67]. For this reason, we can estimate the heat transfer coefficient $h$ from the cooling rate at $T_{\mathrm{g}}$ by:

$$
h=\frac{R * V * c_{\mathrm{p}} * \rho}{S *\left(T_{\mathrm{g}}-T_{\mathrm{f}}\right)}
$$

where $V=L * w * t$ is the volume of the cast $\operatorname{rod}\left(L=75 \mathrm{~mm}\right.$ length of the rod), $c_{\mathrm{p}}$ the specific heat and $\rho$ the density of the BMG, $S=2(L * w+w * t+L * t)$ the surface area and $T_{\mathrm{f}}=298 \mathrm{~K}$ the final temperature of the cast rod, respectively. $c_{\mathrm{P}}$ and $\rho$ are determined by the continuous heating curve of a similar CuZrAl-based BMG and Archimedes' method as $c_{\mathrm{P}} \sim 450 \mathrm{~J} \mathrm{~kg}^{-1}{ }^{\circ} \mathrm{C}^{-1}$ and $\rho=6970 \mathrm{~kg} \mathrm{~m}^{-3}$, respectively [68]. $T_{\mathrm{g}}=700 \mathrm{~K}$ is selected from the $E^{\prime}$ onset in Fig. $4 \mathrm{~b}$ to reflect the mechanical property changes. Inserting these values into the equation (2) yields $\mathrm{h} \sim 4820 \mathrm{~W} \mathrm{~m}^{-2} \mathrm{~K}^{-1}$. From the correlation between the hoop stress vs $h$ in Fig. 6 of ref. [69] the compressive ( $\sigma_{c r e s}$, outer region) and tensile ( $\sigma_{\text {tres, }}$ center region) residual stresses can be estimated as $\sigma_{\text {cres }}=240 \mathrm{MPa}$ and $\sigma_{\text {tres }}=100 \mathrm{MPa}$. The mold material, i.e. whether it is stainless steel or copper, has a negligible influence on the RT stress state of the as-cast BMG rod. This is mainly because the metallic mold is 
elastic throughout the casting process, and the residual stresses in as-cast BMGs are hardly influenced by the mold material and its shape (maximum by 3\%) [69]. Hence, the elastic stresses are relaxed after removing the mold, leaving only the residual stress in the castBMG.

From our previous dilatometry measurements for the same composition, the thermal expansion coefficient can be retrieved as $\alpha=1.124 \times 10^{-5} \mathrm{~K}^{-1}$ [49]. Hence, the continuous heating to $400{ }^{\circ} \mathrm{C}$ from RT creates counter stress according to:

$$
\sigma_{x x}=E(x) * \alpha(x) * \Delta T
$$

where $x$ is an arbitrary direction showing linearity, $E=97 \mathrm{GPa}$ (obtained from the DMA data) and $\Delta T=375 \mathrm{~K}$. If we assume an isotropic stress annihilation, then $\sigma=410 \mathrm{MPa}$. Assuming that a further stress release is possible while temperature stabilization and subsequent rapid quenching to minimize any post-shrinkage, the considered BMG is fully released from the residual stresses.

The complete annihilation of the residual stresses is also reflected in the thermal, thermomechanical and structural properties of the considered CuZr-based MG. As expected, the sample structurally relaxes after the sub- $T_{\mathrm{g}}$ heat treatment, as revealed by the drop in the relaxation enthalpy and $T_{\mathrm{g}}$ registered in Fig. 2. This special heat treatment, on the contrary to general heat treatment processes of MGs around and above $T_{\mathrm{g}}$, increases the thermal stability of the alloy $(\Delta T)$, which can be linked to the percolation of locally favoured clusters within the amorphous matrix which does not lead to observable crystallinity [70]. This change in local scale is also reflected in the new peak at $101^{\circ}$ (corresponding to $d=1.09 \AA$ ) observed by the XRD study in Fig. 1 . The release of the residual stresses results in a plateau with a relatively constant storage modulus of $105 \mathrm{MPa}$ compared to the remarkable stiffening effect observed for the as-cast sample (Fig. 4 and Table 1). Moreover, this stress release yields a significant decrease in $T_{\mathrm{g}}$ measured both

from the $E^{\prime}{ }_{\text {onset }}$ and $E^{\prime \prime}{ }_{\text {peak }}$ and increase in $T_{\mathrm{x}}$ measured from the $\tan \delta_{\text {peak }}$, which in turn increases the $\Delta T$.

\section{Conclusions}

In this contribution, direct evidence is provided that the thermomechanical properties of CuZr-based MGs under sinusoidal oscillating stress being altered by continuous heating to $50{ }^{\circ} \mathrm{C}$ below $T_{\mathrm{g}}$, and rapidly cooled to room temperature after temperature balance. The findings clearly indicate that the sub- $T_{\mathrm{g}}$ heat treatment modifies the short-to-medium range ordering in metallic glass corroborated with the appearance of the $3^{\text {rd }}$ broad hump in XRD. The sub- $T_{\mathrm{g}}$ heat treatment accounts for the stress release which alters the thermomechanical and thermophysical properties. In this regard, the heat-treated sample has high thermal stability and stiffness retention at elevated temperatures.

The key novelties are: (1) This study is a continuous heating and cooling type heat treatment process without having a relatively long term $(\sim 5 \mathrm{~min})$ heat treatment. (2) This is the first time in the literature that influence of the sinusoidal oscillating stress applied via DMA on the thermomechanical properties has been assessed for the heat-treated CuZrbased metallic glasses. (3) This study links the correlation between thermophysical, thermomechanical and structural properties via the adopted heat treatment and the correlated release of the residual stresses.

The metallic shiny and flat samples are bent $\sim 90^{\circ}$ under small amounts of applied static load (25 N) and oscillation displacement $(20 \mu \mathrm{m})$, and the surface becomes oxidized during dynamic mechanical analysis (DMA) three-point bending experiment. The broad, 
amorphous peaks for the as-cast sample do not differ after the heat treatment; however, a small third broad peak at $101^{\circ}$ emerges. The differential scanning calorimetry (DSC) traces indicate an increase in $T_{\mathrm{g}}$ by $5{ }^{\circ} \mathrm{C}$ after heat-treatment. The enthalpy of relaxation $\Delta H_{\text {relax, }}$ on the other hand, decreases significantly from $9.2 \mathrm{~W} \mathrm{~g}^{-1}$ to $5.5 \mathrm{~W} \mathrm{~g}^{-1}$, confirming the changes in the configurational state. DMA performed in the three-point bending mode reveals that $E^{\prime}$ shows a steady profile after sub- $T_{\mathrm{g}}$ annealing. The $T_{\mathrm{g}}$ and crystallization temperature $T_{\mathrm{x}}$ determined from the onset of the decrease in the loss modulus $E^{\prime \prime}$ and the peak positions of $\tan \delta$, respectively, suggests that $T_{\mathrm{g}}$ and $\Delta T$ are larger for the HT $-400^{\circ} \mathrm{C}$ sample in line with the DSC findings. On the other hand, $T_{\mathrm{g}}$ measured from the onset of the storage modulus $E^{\prime}$, indicating the sudden changes in the mechanical properties, is $12{ }^{\circ} \mathrm{C}$ larger for the as-cast state sample. The crystallization temperature $T_{\mathrm{x}}$ of the $\mathrm{HT}-400^{\circ} \mathrm{C}$ sample determined from the $\tan \delta$ is $6{ }^{\circ} \mathrm{C}$ higher, confirming a remarkable difference between the supercooled liquid regions (cf. $\Delta T=54^{\circ} \mathrm{C}$ for as-cast and $\Delta T=72{ }^{\circ} \mathrm{C}$ for HT$400{ }^{\circ} \mathrm{C}$ samples). The unusual increase affirmed by the DSC and DMA analyses is accounted for by the residual stresses imposed on the sample during rapid quenching. The mathematical estimations to find these cumulative stresses yield $240 \mathrm{MPa}$ and $100 \mathrm{MPa}$ on the outer surface and center of the cast plate, respectively. Due to the linear expansion of the cast plates upon continuous heating, the residual stresses can be fully released by the subsequent sub- $T_{\mathrm{g}}$ heat-treatment.

\section{Acknowledgement}

The author thanks Mr. Amir Rezvan, who has prepared the samples and heat-treated the MG for the 3-point bending test. The author gratefully acknowledges the financial support of the Austrian Science Fund (FWF) under project grant I3937-N36 (PI: Baran Sarac).

\section{References}

[1] Liao GY, Chen B, Meng QK, Wang MJ, Zhao XQ. Strain glass in defect-containing ferroelastic Ti44Ni51Nb5 alloy. Rare Metals. 2015; 34: 829 - 832. https://doi.org/10.1007/s12598-014-0229-z

[2] Prasad DS, Ebenezer NS, Shoba C, Pujari SR. Effect of nickel electroplating on the mechanical damping and storage modulus of metal matrix composites. Mater Res Express. 2018; 5: 116409. https://doi.org/10.1088/2053-1591/aadf0b

[3] Kim JT, Soprunyuk V, Chawake N, Zheng YH, Spieckermann F, Hong SH, et al. Outstanding strengthening behavior and dynamic mechanical properties of in-situ AlAl3Ni composites by $\mathrm{Cu}$ addition. Composites, Part B. 2020; 189: 107891. https://doi.org/10.1016/j.compositesb.2020.107891

[4] Junker P, Kochmann DM. Damage-induced mechanical damping in phase-transforming composites materials. Int J Solids Struct. 2017; 113: 132 - 146. https://doi.org/10.1016/i.ijsolstr.2017.01.040

[5] Jin XJ, Liu JY, Jin MJ. Martensitic transformation and precursor phenomena in Au7Cu5Al4 alloys. J Alloys Compd. 2013; 577: S155 - S158. https://doi.org/10.1016/j.jallcom.2012.04.072

[6] Salva HR, Fabietti LM, Ghilarducci AA, Urreta SE. Mechanical damping in nanostructured Nd60Fe30Al10 magnetic alloys. J Alloys Compd. 2010; 495: 420 - 422. https://doi.org/10.1016/j.jallcom.2009.10.012

[7] Wu SK, Chang SH, Chou TY, Tong S. Low-frequency damping properties of dual-phase Mg-xLi-0.5Zn alloys. J Alloys Compd. 2008; 465: 210 - 215. https://doi.org/10.1016/j.jallcom.2007.10.134

[8] Pelletier JM, Perez J, Duffrene L. Mechanical response of an oxide glass to mechanical loading-shear and volume relaxation effects: physical analysis. Acta Mater. 2000; 48: 1397 - 1408. https://doi.org/10.1016/S1359-6454(99)00387-0 
[9] Wang Q, Pelletier JM, Blandin JJ. Thermal stability of cerium-based bulk metallic glasses. Influence of iron addition. J Alloys Compd. 2010; 504: 357 - 361. https://doi.org/10.1016/i.jallcom.2010.05.070

[10] Jeong HT, Fleury E, Kim WT, Kim DH, Hono K. Study on the mechanical relaxations of a Zr36Ti24Be40 amorphous alloy by time-temperature superposition principle. J Phys Soc Jpn. 2004; 73: 3192 - 3197. https://doi.org/10.1143/IPSI.73.3192

[11] Ulutan D, Sima M, Özel T. Prediction of Machining Induced Surface Integrity Using Elastic-Viscoplastic Simulations and Temperature-Dependent Flow Softening Material Models in Titanium and Nickel-Based Alloys. Adv Mater Res. 2011; 223: 401 - 410. https://doi.org/10.4028/www.scientific.net/AMR.223.401

[12] Wang J, Xu Y, Zhang W, Moumni Z. A damage-based elastic-viscoplastic constitutive model for amorphous glassy polycarbonate polymers. Mater Des. 2016; 97: 519 - 531. https://doi.org/10.1016/i.matdes.2016.02.118

[13] Asadian H, Shelesh-Nezhad K. Simulation of dynamic mechanical and viscoelastic behavior in polymer/clay nanocomposites. Polym Compos. 2020; 41: 817 - 823. https://doi.org/10.1002/pc.25412

[14] Wang WH. Dynamic relaxations and relaxation-property relationships in metallic glasses. Prog Mater Sci. 2019; 106: 100561. https://doi.org/10.1016/i.pmatsci.2019.03.006

[15] Datye A, Ketkaew J, Schroers J, Schwarz UD. Effect of the fictive temperature on the modulus, hardness, yield strength, dynamic mechanical and creep response of Zr44Ti11Cu10Ni10Be25 metallic glasses. J Alloys Compd. 2020; 819: 152979. https://doi.org/10.1016/j.jallcom.2019.152979

[16] Qiao JC, Chen YH, Casalini R, Pelletier JM, Yao Y. Main $\alpha$ relaxation and slow $\beta$ relaxation processes in a La30Ce30Al15Co25 metallic glass. J Mater Sci Technol. 2019; 35: 982 - 986. https://doi.org/10.1016/i.jmst.2018.12.003

[17] Sergiienko RA, Shcheretskyi OA, Zadorozhnyy VY, Verkhovliuk AM, Louzguine-Luzgin DV. Investigation of Zr55Cu30Al10Ni5 bulk amorphous alloy crystallization. J Alloys Compd. 2019; 791: 477 - 482. https://doi.org/10.1016/j.jallcom.2019.03.270

[18] Louzguine-Luzgin DV, Zadorozhnyy MY, Ketov SV, Jiang J, Golovin IS, Aronin AS. Influence of cyclic loading on the structure and double-stage structure relaxation behavior of a Zr-Cu-Fe-Al metallic glass. Mater Sci Eng, A. 2019; 742: 526 - 531. https://doi.org/10.1016/j.msea.2018.11.031

[19] Ruta B, Pineda E, Evenson Z. Relaxation processes and physical aging in metallic glasses. J Phys: Condens Matter. 2017; 29: 503002. https://doi.org/10.1088/1361648X/aa9964

[20] Qiao JC, Wang Q, Pelletier JM, Yao Y. Relaxation of Ni-free Ti40Zr10Cu36Pd14 bulk metallic glass under mechanical stress. Intermetallics. 2018; 102: 6 - 10. https://doi.org/10.1016/j.intermet.2018.08.009

[21] Qiao JC, Cong J, Wang Q, Pelletier JM, Yao Y. Effects of iron addition on the dynamic mechanical relaxation of Zr55Cu30 Ni5Al10 bulk metallic glasses. J Alloys Compd. 2018; 749: 262 - 267. https://doi.org/10.1016/i.jallcom.2018.03.285

[22] Frey M, Busch R, Possart W, Gallino I. On the thermodynamics, kinetics, and sub-Tg relaxations of Mg-based bulk metallic glasses. Acta Mater. 2018; 155: 117 - 127. https://doi.org/10.1016/j.actamat.2018.05.063

[23] Yamada R, Tanaka N, Guo W, Saida J. Crystallization behavior of thermally rejuvenated Zr50Cu40Al10 metallic glass. Mater Trans. 2017; 58: 1463 - 1468. https://doi.org/10.2320/matertrans.MAW201703

[24] Sarac B, Spieckermann F, Rezvan A, Gammer C, Krämer L, Kim JT, et al. Annealingassisted high-pressure torsion in Zr55Cu30Al10Ni5 metallic glass. J Alloys Compd. 2019; 784: 1323 - 1333. https://doi.org/10.1016/i.jallcom.2019.01.063 
[25] Yavari AR, Le Moulec A, Inoue A, Nishiyama N, Lupu N, Matsubara E, et al. Excess free volume in metallic glasses measured by X-ray diffraction. Acta Mater. 2005; 53: 1611 1619. https://doi.org/10.1016/j.actamat.2004.12.011

[26] Ruta B, Chushkin Y, Monaco G, Cipelletti L, Giordano VM, Pineda E, et al. Relaxation dynamics and aging in structural glasses. AIP Conf Proc. 2013; 1518: 181 - 188. https://doi.org/10.1063/1.4794566

[27] Jakse N, Pasturel A. Coupling between dynamic slowing down and chemical heterogeneity in a metallic undercooled liquid. Phys Rev B. 2017; 95: 144210. https://doi.org/10.1103/PhysRevB.95.144210

[28] Yu HB, Wang WH, Samwer K. The $\beta$ relaxation in metallic glasses: an overview. Mater Today. 2013; 16: 183 - 191. https://doi.org/10.1016/i.mattod.2013.05.002

[29] Qiao JC, Casalini R, Pelletier JM. Main ( $\alpha$ ) relaxation and excess wing in Zr50Cu40Al10 bulk metallic glass investigated by mechanical spectroscopy. J Non-Cryst Solids. 2015; 407: 106 - 109. https://doi.org/10.1016/j.jnoncrysol.2014.08.009

[30] Dyre JC. Colloquium: The glass transition and elastic models of glass-forming liquids. Rev Mod Phys. 2006; 78: 953 - 972. https://doi.org/10.1103/RevModPhys.78.953

[31] Angell CA, Ngai KL, McKenna GB, McMillan PF, Martin SW. Relaxation in glassforming liquids and amorphous solids. J Appl Phys. 2000; 88: 3113 - 3157. https://doi.org/10.1063/1.1286035

[32] Liu XF, Zhang B, Wen P, Wang WH. The slow $\beta$-relaxation observed in Ce-based bulk metallic glass-forming supercooled liquid. J Non-Cryst Solids. 2006; 352: 4013 - 4016. https://doi.org/10.1016/j.jnoncrysol.2006.08.006

[33] Wang Z, Yu HB, Wen P, Bai HY, Wang WH. Pronounced slow $\beta$-relaxation in La-based bulk metallic glasses. J Phys: Condens Matter. 2011; 23: 142202. https://doi.org/10.1088/0953-8984/23/14/142202

[34] Hachenberg J, Samwer K. Indications for a slow $\beta$-relaxation in a fragile metallic glass. J Non-Cryst Solids. 2006; 352: $5110 \quad$ - 5113. https://doi.org/10.1016/i.jnoncrysol.2006.01.143

[35] Zhao ZF, Wen P, Shek CH, Wang WH. Measurements of slow $\beta$-relaxations in metallic glasses and supercooled liquids. Phys Rev B. 2007; 75: 174201. https://doi.org/10.1103/PhysRevB.75.174201

[36] Groza JR, Shackelford JF. Materials Processing Handbook. CRC Press, Boca Raton, FL, USA, 2007. https://doi.org/10.1201/9780849332166

[37] Inoue A, Zhang T, Kurosaka K, Zhang W. High-strength Cu-based bulk glassy alloys in $\mathrm{Cu}-\mathrm{Zr}-\mathrm{Ti}-\mathrm{Be}$ system. Mater Trans. 2001; 42: 1800 - 1804. https://doi.org/10.2320/matertrans.42.1800

[38] Tian L, Cheng YQ, Shan ZW, Li J, Wang CC, Han XD, et al. Approaching the ideal elastic limit of metallic glasses. Nat Commun. 2012; 3 : 609. https://doi.org/10.1038/ncomms1619

[39] Shan ZW, Li J, Cheng YQ, Minor AM, Asif SAS, Warren OL, et al. Plastic flow and failure resistance of metallic glass: Insight from in situ compression of nanopillars. Phys Rev B. 2008; 77: 155419. https://doi.org/10.1103/PhysRevB.77.155419

[40] Guo H, Yan PF, Wang YB, Tan J, Zhang ZF, Sui ML, et al. Tensile ductility and necking of metallic glass. Nat Mater. 2007; 6: 735 - 739. https://doi.org/10.1038/nmat1984

[41] Ashby MF, Greer AL. Metallic glasses as structural materials. Scr Mater. 2006; 54: 321 - 326. https://doi.org/10.1016/i.scriptamat.2005.09.051

[42] Kumar G, Rector D, Conner RD, Schroers J. Embrittlement of Zr-based bulk metallic $\begin{array}{lllll}\text { glasses. } & \text { Acta } & \text { Mater. 2009; } & 3572 & -\end{array}$ https://doi.org/10.1016/j.actamat.2009.04.016

[43] Li WD, Gao YF, Bei HB. On the correlation between microscopic structural heterogeneity and embrittlement behavior in metallic glasses. Sci Rep. 2015; 5: 14786. https://doi.org/10.1038/srep14786 
[44] Schuh CA, Hufnagel TC, Ramamurty U. Overview No.144 - Mechanical behavior of amorphous alloys. Acta Mater. 2007; 55: 4067 - 4109. https://doi.org/10.1016/i.actamat.2007.01.052

[45] Sarac B, Schroers J. Designing tensile ductility in metallic glasses. Nat Commun. 2013; 4: 2158. https://doi.org/10.1038/ncomms3158

[46] Sarac B, Ketkaew J, Popnoe DO, Schroers J. Honeycomb Structures of Bulk Metallic Glasses. Adv Funct Mater. 2012; 22: $3161 \quad$ - 3169. https://doi.org/10.1002/adfm.201200539

[47] Wei R, Wang XL, Yang S, Jiang F, He L. Formation of CuZr-based bulk metallic glass composites containing nanometer-scale B2-CuZr phase through sub-Tg annealing. J Alloys Compd. 2014; 617: 699 - 706. https://doi.org/10.1016/j.jallcom.2014.08.045

[48] Wei R, Yang S, Chang Y, Li YF, Zhang CJ, He L. Mechanical property degradation of a CuZr-based bulk metallic glass composite induced by sub-Tg annealing. Mater Design. 2014; 56: 128 - 138. https://doi.org/10.1016/j.matdes.2013.11.001

[49] Sarac B, Zhang L, Kosiba K, Pauly S, Stoica M, Eckert J. Towards the Better: Intrinsic Property Amelioration in Bulk Metallic Glasses. Sci Rep. 2016; 6: 27271. https://doi.org/10.1038/srep27271

[50] Murali P, Ramamurty U. Embrittlement of a bulk metallic glass due to sub-Tg annealing. Acta Mater. 2005; 53: $1467 \quad$ - 1478. https://doi.org/10.1016/i.actamat.2004.11.040

[51] Hayat F, Yin J, Tabassum A, Hou H, Lan S, Feng T. Effects of cooling rate and sub-Tg annealing on Ni80P20 metallic glass: A molecular dynamic (MD) study. Comput Mater Sci. 2020; 179: 109681. https://doi.org/10.1016/j.commatsci.2020.109681

[52] Zhang P, Maldonis JJ, Besser MF, Kramer MJ, Voyles PM. Medium-range structure and glass forming ability in Zr-Cu-Al bulk metallic glasses. Acta Mater. 2016; 109: 103 - 114. https://doi.org/10.1016/i.actamat.2016.02.006

[53] Kosiba K, Pauly S. Inductive flash-annealing of bulk metallic glasses. Sci Rep. 2017; 7: 2151. https://doi.org/10.1038/s41598-017-02376-X

[54] Haruyama O, Yoshikawa K, Yamazaki Y, Yokoyama Y, Egami T. Comparison of Structural Relaxation Behavior in As-Cast and Pre-Annealed Zr-Based Bulk Metallic Glasses Just below Glass Transition. Mater Trans. 2015; 56: 648 - 654. https://doi.org/10.2320/matertrans.M2015023

[55] Song M, Liao XZ, He YH. Effect of sub-T-g annealing on the mechanical properties of a ZrAlNiCuNb bulk metallic glass. Phil Mag Lett. 2011; 91: 713 - 723. https://doi.org/10.1080/09500839.2011.609842

[56] Kumar G, Neibecker P, Liu YH, Schroers J. Critical fictive temperature for plasticity in metallic glasses. Nat Commun. 2013; 4: 1536. https://doi.org/10.1038/ncomms2546

[57] Scudino S, Kuhn U, Schultz L, Nagahama D, Hono K, Eckert J. Microstructure evolution upon devitrification and crystallization kinetics of Zr57Ti8Nb2.5Cu13.9Ni11.1Al7.5 melt-spun glassy ribbon. J Appl Phys. 2004; 95: 3397 - 3403. https://doi.org/10.1063/1.1652244

[58] Van Steenberge N, Concustell A, Sort J, Das J, Mattern N, Gebert A, et al. Microstructural inhomogeneities introduced in a Zr-based bulk metallic glass upon low-temperature annealing. Mater Sci Eng, A. 2008; 491: 124 - 130. https://doi.org/10.1016/j.msea.2008.01.083

[59] Stoica M, Van Steenberge N, Bednarčik J, Mattern N, Franz H, Eckert J. Changes in short-range order of Zr55Cu30Al10Ni5 and Zr55Cu20Al10Ni10Ti5 BMGs upon

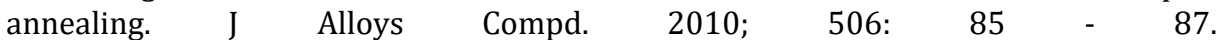
https://doi.org/10.1016/i.jallcom.2010.07.001

[60] Hajlaoui K, Benameur T, Vaughan G, Yavari AR. Thermal expansion and indentationinduced free volume in Zr-based metallic glasses measured by real-time diffraction using synchrotron radiation. Scr Mater. 2004; 51: 843 - 848. https://doi.org/10.1016/i.scriptamat.2004.07.008 
[61] Sarac B, Bernasconi A, Wright J, Stoica M, Spieckermann F, Mühlbacher M, et al. Structural modifications in sub-Tg annealed CuZr-based metallic glass Mater Sci Eng, A. 2017; 707: 245 - 252. https://doi.org/10.1016/j.msea.2017.09.013

[62] Cullity BD. Diffraction I: Directions of Diffracted Beams. 2nd ed: Addison-Wesley Publishing Company Inc., Reading, MA, USA, 1978.

[63] Busch R, Schroers J, Wang WH. Thermodynamics and kinetics of bulk metallic glass. Mrs Bull. 2007; 32: 620-623. https://doi.org/10.1557/mrs2007.122

[64] Schroers J. The superplastic forming of bulk metallic glasses. JOM. 2005; 57: 35 - 39. https://doi.org/10.1007/s11837-005-0093-2

[65] Sarac B, Kumar G, Hodges T, Ding SY, Desai A, Schroers J. Three-Dimensional Shell Fabrication Using Blow Molding of Bulk Metallic Glass. J Microelectromech Syst. 2011; 20: 28 - 36. https://doi.org/10.1109/IMEMS.2010.2090495

[66] Yang GN, Shao Y, Yao KF, Chen SQ. A study of cooling process in bulk metallic glasses fabrication. Aip Adv. 2015; 5: 117111 https://doi.org/10.1063/1.4935440

[67] Debenedetti PG, Stillinger FH. Supercooled liquids and the glass transition. Nature. 2001; 410: 259 - 267. https://doi.org/10.1038/35065704

[68] $\mathrm{Wu} \mathrm{K}, \mathrm{Li} \mathrm{R}$, Zhang $\mathrm{T}$. Crystallization and thermophysical properties of Cu46Zr47Al6Co1 bulk metallic glass. Aip Adv. 2013; 3: 112115. https://doi.org/10.1063/1.4832235

[69] Aydiner CC, Üstündag E. Residual stresses in a bulk metallic glass cylinder induced by thermal tempering. Mech Mater. 2005; 37: 201 - 212. https://doi.org/10.1016/i.mechmat.2004.03.001

[70] Wu ZW, Li FX, Huo CW, Li MZ, Wang WH, Liu KX. Critical scaling of icosahedral medium-range order in CuZr metallic glass-forming liquids. Sci Rep. 2016; 6: 35967. https://doi.org/10.1038/srep35967 